\title{
A perspective on the development and sustainability of nutrition surveillance in low-income countries
}

Veronica Tuffrey

\begin{abstract}
Background: Many varied activities are encompassed by the term "nutrition(al) surveillance". Several national surveillance systems were initiated soon after the World Food Conference in 1974, but few have lasted. Most were complex, expensive, slow to produce findings, and were eventually stopped. This paper discusses why nutrition surveillance in low-income countries is so hard to sustain, and identifies the key factors in systems which have been maintained.

Discussion: For nutrition surveillance activities to be sustainable, there needs to be: demand for the information; a reasonable cost as well as a cost-efficient process; speedy generation and dissemination of good quality information; secure allocation of resources from the government and/or donor; and a central, organizing institution for strong coordination of data collection, analysis, interpretation and communication. Investment in local individual and institutional capacity plus the retention of experienced staff are important. A periodic evaluation of the process should be an integral part of surveillance activities. For national systems the ideal coordinating institution should sit within a government structure separate from those with direct involvement in health or agriculture, such as a ministry of planning, as those who lead the surveillance must be independent of decision-makers but need to understand and prioritise their needs for information. The findings need to be communicated clearly and the means of presentation adapted to different audiences. To promote participation, the findings should be shared with stakeholders at all levels.

Summary: This review of the development of nutrition surveillance in low-income countries over the last 40 years finds that sustainability hinges on cost, capacity development, location of the institutional base, demand for the products, and participation. These considerations are noteworthy given the pivotal role of nutrition surveillance information in national and sub-national policy-making, planning and programming. Information from nutrition surveillance also provides an increasingly important mechanism to hold governments to account and to allow progress towards international targets to be tracked.
\end{abstract}

Keywords: Nutrition assessment, Public health, Surveillance, Anthropometry, Malnutrition, Timely warning, Food security, Program evaluation, Policy, Low-income

\section{Background}

Public health surveillance is defined by the $\mathrm{WHO}$ as "the continuous, systematic collection, analysis and interpretation of health-related data needed for the planning, implementation, and evaluation of public health practice" [1]. As part of this broad activity, nutrition surveillance in low-income countries brings together data relating to

Correspondence: veronica.tuffrey@blueyonder.co.uk

Faculty of Science and Technology, University of Westminster, 115, New Cavendish Street, London W1W 6UW, UK both nutritional outcomes and exposures, as suggested in the first official guidance: "Surveillance should provide ongoing information about the nutritional conditions of the population and the factors that influence them" [2]. Nutrition differs somewhat from other health outcomes for which surveillance systems exist. First there is a huge range of causal influences from many different sectors on human nutrition including agriculture, health, social protection, early childhood development, education, and water and sanitation. Second, the public health impact and consequent economic impact of the outcome - 
malnutrition - may be profound. Several studies provide estimates of the economic losses attributable to undernutrition [3-6]. Economic models suggest that the returns on investments in nutrition have high benefit to cost ratios and that preventing malnutrition should be a top development priority [7]. It is recognised that undernutrition has been neglected in international development programmes in recent years despite the persistently high rates of chronic undernutrition, and recently there have been renewed efforts to reduce these rates [8].

Over the past 40 years information derived from nutrition surveillance has been used in several ways, most notably to monitor the nutrition situation, identify factors associated with malnutrition, inform nutrition policy making and programming, track progress towards achieving goals, serve as an early warning of increased nutritional risk, assess the delivery and coverage of services, and contribute to programme evaluation. There are numerous mechanisms for the regular and systematic collection of data on nutritional indicators from regional to community levels which involve various stakeholders. The methods used for data collection in nutrition surveillance are reviewed in a forthcoming paper, whilst in this paper the mechanisms relating to the governance of nutrition surveillance and its sustainability are considered.

It is timely to review these issues given the current political momentum to reduce the numbers of children affected by undernutrition, and because of the commitments made to this end by national governments, international organisations, and donors. For example in May 2012, health leaders worldwide adopted the World Health Assembly (WHA) Comprehensive Implementation Plan on Maternal, Infant and Young Child Nutrition. They agreed to commit to a number of targets to be achieved by 2025 , known as the WHA global targets, including a reduction of $40 \%$ in the number of stunted children in the world (against global estimates for 2010), and a reduction of the prevalence of wasting to $5 \%$ [9]. These targets were integrated into the second of the Post-2015 Sustainable Development Goals [10]. In 2013 at the Nutrition for Growth summit in London, a set of individual commitments to beat hunger and improve nutrition were made including a commitment of USD4.15 billion to scale up nutrition specific actions by 2020 [8]. Many countries recently signed the Declaration of the Second International Conference on Nutrition and committed themselves to taking action on nutrition on several fronts [11]. However, despite the development and application of varied methods of nutrition data collection over the last four decades, existing sources of data are insufficient to track progress towards these internationally agreed goals and to help allocate the funds needed for nutrition initiatives [12] a fact that was highlighted in recent Global Nutrition Reports [13, 14].

Another stimulus for reviewing experience in nutrition surveillance now is the instability of the environment within which much of the world's chronically poor and malnourished population live. The combination of climate change, rapid population growth, conflict, and food price volatility already appears to have pushed several poor regions into states of permanent crisis, and there is an urgent need both to assess situations and to build resilience to shocks and stresses due to natural and man-made disasters [15].

Over the last decade, our understanding of the harmful short- and long-term consequences of undernutrition for individuals, communities and nations has increased, and the extensive costs and losses it causes including morbidity, mortality and impaired cognitive development are more widely recognised [16, 17]. Existing evidence on what works to prevent maternal and child undernutrition has been well summarised [18, 19]. Attention is also now being focussed on identifying factors relating to the context in which nutrition programmes are delivered to make them cost-effective and sustainable, and how those factors can be favourably influenced [20]. This emphasis on political as well as technical issues is a new development in the discourse on tackling poor nutrition, and an important additional sphere of action has been identified relating to the processes and environments that shape and support policy development and execution. The intention of this paper is to examine these governance issues related to nutrition surveillance, while the technical issues involved with the design of systems and the methods for data collection are reviewed in a separate paper.

The body of literature published on nutrition surveillance in low-income countries is not extensive. Before the mid 1990's papers and reports mainly relate to guidance around setting up surveillance systems for example $[2,21-25]$, with a few descriptions of the design and implementation of systems [26-30]. From the mid-1990s onwards, and particularly since the year 2000, the literature mainly relates to findings from further analysis of surveillance data to address questions of international significance, and descriptions of the surveillance systems are provided in the methods sections of the papers. These questions relate mainly to micronutrient deficiencies or programmes to control them (for example [31-33]). Other public health issues addressed by researchers using surveillance data have been the double burden of malnutrition [34], and the link between anthropometric status and tobacco use [35], expenditure on rice [36, 37] and education [38]. Reviews are rare [21, 39-41] with the most recent of these relating to surveillance in humanitarian settings [41]. In 2013 updated guidance for national systems was published by the WHO Regional Office for the Eastern 
Mediterranean [42], and an inventory of systems run by government public health authorities was produced by the US Food and Nutrition Technical Assistance Project in 2014 [43]. Findings from a narrative review of the literature will be published elsewhere (Tuffrey, V. Nutrition surveillance systems: their use and value. London: Save the Children and Transform Nutrition, forthcoming.).

This paper explores why nutrition surveillance in lowincome countries is so hard to sustain, and identifies the key factors in systems which have been maintained. The paper summarises the development of nutrition surveillance over the last 40 years, and discusses its main applications; discusses factors associated with the sustainability of past systems; and finally examines other issues which may be critical for sustainable surveillance in the future. Together with the forthcoming paper which addresses the technical issues (Tuffrey V, Hall A. Methods of nutrition surveillance in low-income countries. Emerging Themes in Epidemiology, forthcoming.) the aim is to aid practitioners and agencies to amend or design costeffective and sustainable nutrition surveillance activities in order to reduce poor nutrition in low-income countries.

\section{Discussion}

\section{Development of nutrition surveillance}

The basis of nutrition surveillance can be traced back 100 years. Beginning just after World War I and increasingly during and after World War II, the international community collected data on national food balance-sheets to assist in efforts to allocate and distribute food in regions affected by conflict [44]. In 1948 the Universal Declaration of Human Rights made pledges to improve food security and reduce under-nutrition [45]. By the early 1970s increased efforts were being made to collect information on food and nutrition to support decision-making as a result of declining global food stocks and rising prices, and because of famines in the Sahel and Bangladesh due to drought and floods respectively [46]. After these crises the term "food security" became current, defined at the first World Food Summit as the "availability at all times of adequate world food supplies of basic foodstuffs to sustain a steady expansion of food consumption and to offset fluctuations in production and prices" [47] thus reflecting existing concerns about the global volume and stability of food supplies.

At the time of the 1974. World Food Conference, local malnutrition was viewed to be a result of a global food supply problem. At that conference, a universal declaration on the eradication of hunger and malnutrition was adopted. Also the establishment of a global nutritional surveillance system was proposed as a key strategy to alleviate hunger as well as the creation of the Global Information and Early Warning System on Food and Agriculture (GIEWS) within the Food and Agricultural Organisation (FAO), and the formation of the World Food
Programme (WFP). The World Health Organization (WHO) as lead agency, together with the FAO and UNICEF were invited to establish the global nutrition surveillance system, and its methods were developed by an expert committee. Their report did not include a clear definition of nutrition surveillance, but its general objective was described as follows: "Surveillance should provide ongoing information about the nutritional conditions of the population and the factors that influence them. This information will provide the basis for decisions to be made by those responsible for policy, planning and the management of programmes relating to improvement of food consumption patterns and nutritional status" [2]. The committee recognised that for a global system to exist, action was first needed to develop national systems.

After the World Food Conference in 1974 there was considerable activity to set up national surveillance systems. Most countries had in place at least some elements which might contribute information, such as processes to monitor food supplies and economic conditions, plus data from clinic-based growth monitoring. An early review indicated that the challenge for nutritionists was to bring these elements together to create a coherent system and "to persuade decision-makers of the usefulness of such information" [39]. Thus it is noteworthy that apparently even at the earliest stage in the development of nutrition surveillance, the source of motivation for national governments to set up systems was not the potential users of the information. In the 1970s, nutrition surveillance activities were strongly supported by bilateral donors including the United States Agency for International Development (USAID) and the Swedish International Development Agency (SIDA). Academic institutions were also involved to provide technical assistance and training, the most active of which was Cornell University.

Initial experiences were reviewed in 1979 and the findings disseminated through regional workshops in Cali, Colombia in 1981 [21] and Nairobi, Kenya in 1982 [48]. Further guidance was published which provided the definition of nutrition surveillance which is most often quoted nowadays: ". to watch over nutrition, in order to make decisions which lead to improvements in nutrition in populations" [21]. By now the discussion of the causes of malnutrition had become more complex. Food and nonfood factors were distinguished, and the importance of poverty as an antecedent factor was acknowledged. In parallel, the definition of food security was revised in 1983 and now stated that food security required both "..physical and economic access to basic food", to reflect the entitlement approach advocated by the economist Amartya Sen [49].

In parallel, national early warning systems to predict food shortages were developed, some with the support of the FAO, and monitoring nutritional status was included as a component. The most notable of these 
systems were in Botswana [50], Ethiopia [51], and Indonesia [30]. By the early 1980s national surveillance systems existed in about 20 countries [52]. Most were national or regional in scope and were based primarily on data on growth monitoring from clinics with infrequent additional surveys, while a few school-census systems existed, mainly in Central America. Some systems which started at this time have lasted and were useful, but many had complex and expensive data collection systems which generated information slowly that was of little use, so most eventually collapsed [40].

Since the 1980s many countries and agencies have continued to undertake surveillance activities, but their work has rarely been documented and shared in the literature apart from a surge of interest in the early 1990s. A series of papers from a conference in Adelaide held in 1993 were published in an issue of the Food and Nutrition Bulletin [53], and another series of papers was published on systems of food security and nutritional surveillance in Africa in a special issue of the journal Food Policy [54].

A number of elements in the nutrition landscape of the early 1990s had an impact on nutrition surveillance. First, the UNICEF conceptual framework of malnutrition was developed in 1990 in which three proximal determinants of nutritional status were identified: basic health services and a healthy environment; household food security; and maternal and child care [55]. The recognition that care was a separate causal factor focussed the attention of surveillance on indicators related to behaviours that influence nutrition, such breastfeeding practices. Second, the concept of "utilisation" was incorporated into the definition of food security to reflect the importance of non-food factors such as disease due to poor hygiene, and nutrition data were increasingly used in surveillance of food insecurity (see below) [56]. Third, the first inter-governmental meeting on nutrition was held in 1992, called the International Conference on Nutrition, at which nutritional surveillance was adopted as one of the nine strategies in the World-wide Plan of Action on Nutrition ([57] p.33).

From the mid-1990s, two themes in the international context increased in importance and influenced the development of nutrition surveillance activities. The first was the increased priority given to surveillance of food security, and the development of methods to do this. At the World Food Summit in 1996, participants from 185 countries endorsed the establishment by governments of mechanisms to collect information on the nutritional status of all members of their communities to monitor and improve their household food security. A Food Insecurity and Vulnerability Information and Mapping System (FIVIMS) was created by the FAO and, in parallel, organisations concerned with food and nutrition security at a local level developed approaches for more regular and context-specific data systems [44]. Today there are several accepted approaches for assessing household food security. Some, such as the Household Economy Approach, the Individual Household Method and Nutrition Causal Analysis, gather data using qualitative and quantitative methods from non-random samples of households, while others, such as the Comprehensive Food Security and Vulnerability Analysis undertaken by the WFP, collect data using cross-sectional, random sample surveys [58]. There are also tools which can be added to these standardised approaches including the Household Dietary Diversity Score (HDDS), the Household Hunger Scale (HHS) and the Coping Strategies Index (CSI). In contrast, there is only one standardised approach to assessing childrens' anthropometric status, and this applies the set of procedures known as SMART (Standardized Monitoring and Assessment of Relief and Transitions) surveys [59].

The second theme which influenced the development of surveillance activities after the mid-1990s was the control of micronutrient deficiencies. Evidence of the impact on health of micronutrient deficiencies, plus the existence of technologies to provide micronutrients at large scale and low cost enabled the prioritisation of micronutrient malnutrition control and led to a need for relevant data. The biomarkers of haemoglobin concentration and serum retinol concentration were added to some surveillance systems. Surveillance data were used to answer questions about micronutrient deficiencies or about programmes to control them, particularly in two countries with well-functioning nutritional surveillance systems, Bangladesh and Indonesia [60-63]. A global system for the surveillance of vitamin and mineral nutrition was established in 1991, managed by the Department of Nutrition for Health and Development in the WHO [64].

Thus over the last 20 years or so, there has been a huge expansion in the amount of data collected on nutrition and nutrition-related factors. The types of data, the approaches used to collect them and the frequency of collection, depend on the administrative level. Nationally representative surveys are usually undertaken every 4 to 5 years by the USAID-supported Demographic and Health Surveys (DHS) and the UNICEF-supported Multiple Indicator Cluster Surveys (MICS), while a few countries have mounted their own nationally representative surveys, usually based on versions of the DHS and MICS protocols [65]. Household consumption and expenditure surveys (HCESs) contain a great deal of information about food acquisition and consumption and are undertaken every 3-5 years in more than 125 countries [66]. Other types of national-level surveys exist which collect nutrition data including the Living Standards Measurement Study (LSMS) and the Core Welfare Indicator Questionnaire survey [67]. At district and 
community level, agencies such as ACF, Care, and Save the Children undertake systematic and regular assessments of anthropometric status and food security with differing amounts of integration between these two types of assessments [58].

As a response to the multiplicity of methods, international symposia were organised by the FAO $[68,69]$. At the second of these conferences, a persistent topic was the need for a coordinated approach whereby different agencies would focus on a core set of common indicators of food security which could be assessed consistently to facilitate an analysis of trends and enable comparisons to be made between countries. The poor links between information and decision-making was also frequently noted. Attention was drawn to the lack of data sources that adequately capture seasonality and other forms of intra- and inter-annual variation in food security, or to provide the geographic level of disaggregation needed to inform accurate targeting [69]. To help resolve these deficits in data, it was suggested that anthropometric measurements of children could be included in existing national-level surveys, and possibly measurements of adults too [67].

Further guidance on surveillance was published in 2013 [42] in which the definition of surveillance relates to policy-making rather than decision-making as follows: "A food and nutrition surveillance system is a mechanism to transfer food and nutrition data into action through formulation, modification and application of the food and nutrition policy of a country"1. Much of the new guidance related to institutional aspects of nutrition surveillance. There are currently around 30 nationallevel systems operated under the auspices of government public health authorities [43].

In summary, despite over 40 years having passed since the start of formal nutrition surveillance initiatives, there are major unresolved issues. There is little consensus on the best methods to undertake nutrition surveillance [41] and many systems have been short-lived, yet few evaluations were done to learn why. It was recently noted that although nutrition surveillance is more typically associated with acute crises, it can also be an extremely valuable tool in a development context [43]. With this in mind, the next section considers the main applications of information derived from nutrition surveillance activities. Table 1 includes details of the governance of three surveillance systems, those of Bangladesh, Ethiopia and Malawi, to provide context for the issues described in the following two sections. These systems were selected because they provide a geographical spread; they encompass the two major objectives of surveillance, long-term monitoring for policy and planning and timely warning; and literature describing the systems was available, including evaluations.

\section{Uses of surveillance information}

Mason and colleagues classified surveillance activities by purpose as follows: for long-term nutritional monitoring; to evaluate the impact of programmes and projects; and as early-warning systems [21]. It was soon noted that systems were often founded with the intention to serve more than one function, so in practice the distinction between these types of surveillance was not clear, and the extent to which the information was used for the anticipated purposes was rarely evaluated [39]. Even now very few impartial evaluations of the use and value of surveillance information have been done and reported. The most common applications of surveillance information are briefly examined below, with examples. The methods used in nutrition surveillance are discussed elsewhere (Tuffrey V, Hall A. Methods of nutrition surveillance in low-income countries. Emerging Themes in Epidemiology, forthcoming.).

\section{Long-term monitoring for national and local policy and planning}

Tracking the relationship between surveillance data and changes in policy is not easy, and few examples are available from the literature. Information provided by national surveillance systems based on growth monitoring have provided guidance to formulate general national nutrition policies and plans, for example in Sri Lanka, Costa Rica, Kenya and the Philippines [39], even though such data are not ideal, as they are not representative of the whole population. Data collected by the Nutritional Surveillance Project (NSP, Table 1) in Bangladesh were used to emphasize the need for vitamin A supplements (VAS) for all 6-59 month old children to prevent night blindness, and so influenced the development of the VAS programme, while findings from the NSP in 1997-8 led to the extension of the period after delivery that a mother can be given vitamin A from 2 to 6 weeks [70]. In Indonesia the Ministry of Health used Nutrition and Health Surveillance System (NSS) data as a basis to formulate policy on anaemia control and used haemoglobin data as a sensitive indicator of economic difficulties. The findings of the NSS on breastfeeding and complementary feeding practices in the 2002 annual report were also used to promote and support breastfeeding activities in Indonesia which led to a change in national breastfeeding recommendations [71].

Nationally representative data have been collected every few years by the DHS and MICS which enable long-term trends to be detected and progress to be monitored towards international targets, such as the first Millennium Development Goal and the WHA global targets [72]. Such time series data can be used to help understand how changes in exposures or the increase in programmes may be driving down the incidence of undernutrition [73]. However for detailed policy and planning purposes these surveys are not frequent enough 
Table 1 Three case studies of nutrition surveillance system administration in low-income countries

case study

Governance

Financial support

Objective

Methods of information dissemination
The Nutrition Surveillance Project (NSP) and the Food Security and Nutrition surveillance Project (FSNSP), Bangladesh 1990-present ([70, 142, 143], and Tuffrey, V. Nutrition surveillance systems: their use and value. London: Save the Children and Transform Nutrition, forthcoming.).

There has been a national surveillance system in Bangladesh covering most of the country for the last 25 years, except for a break between 2006 and 2009. The Nutrition Surveillance Project (NSP), which 2009. The Nutrition Surveillance Project (NSP), which
operated between 1990 and 2006 was established operated between 1990 and 2006 was establish
by the NGO Helen Keller International (HKI) in by the NGO Helen Keller International (HKI) in partnership with the national Institute of Public mostly national NGOs who employed staff to collect and enter the data. The successor to the NSP, the Food Security and Nutrition Surveillance NSP, the Food security and Nutrition Surveillanc Project (FSNSP), has operated since 2009 as partnership between HKI, the James P Grant Schoo of Public Health (JPGSPH) of BRAC University and the Bangladesh Bureau of Statistics, part of the Ministry of Planning. The FSNSP collects

anthropometric, food security, socio-economic and environmental data.

Funded by USAID between 1990 and 2002, the Dutch government between 2002 and 2006, and the EU from 2009 to present day.

Initially timely warning, but as the number of regions covered increased, the system became more of a tool for national and local policy and planning.

- Bulletins providing information on a specific topic - Presentations to the government, NGO partners, donors and at national and international scientific conferences.

- Scientific papers, for example on vitamin A capsule distribution, homestead food production rice prices and malnutrition. - A book.

Comment from evaluation [68]: Some stakeholders found the bulletins were appropriate for nutrition experts only. It was suggested that an additional short and simple report in the local language, Bangla, should be produced.

Note: These points refer to the NSP after 2000.
The Nutrition Surveillance Programme (NSP)

Ethiopia 1986-2001 [95, 144].

Save the Children UK funded and implemented a surveillance system between 1986 until 2001 which generated data on anthropometry and food

security. Fifteen survey areas were purposively

selected to include the most famine-prone areas of the country. The NSP provided information for the Ethiopian government's Early Warning System (EWS) within the Relief and Rehabilitation Commission (RRC). The EWS had its own Nutrition Unit, but this was poorly resourced and the EWS was mainly dependent upon NGOs such as Save the Children and Care for nutrition data.

Save the Children both funded and implemented the system.

\section{Timely warning}

- From 1995 there were two publications: NSP Reports and NSP Focus. These were distributed to around 20 donors, NGOs and other external agencies, and within the Disaster Prevention and Preparedness Commission (DPPC) and other government agencies.

government agencies.

in the fedea DPPC Ealy Waning Gro meetings and contributed to discussions about needs.

Comment from evaluation [93]: Information was presented regularly in a format that was easy to understand, but not enough attention was given to ensuring a response.
The Integrated Nutrition and Food Security Surveillance System (INFSS), Malawi 2003-2008 $[77,93,145,146]$

This clinic-based sentinel system was designed and coordinated by ACF and implemented between 2003 and 2008 in partnership with the Ministry of Health and Ministry of Agriculture. The INFSS system provided information on trends in nutrition among children aged less than 5 years and their households' food security situation, and the system covered most of the country ( 26 out of 28 districts).
Funded by the EU, with technical support from UNICEF and the FAO.

Timely warning, and a tool for national planning.

- Each month a bulletin was issued, with the results of the data analysis presented by district and livelihood zone showing trends over time for information on both nutrition and food security. - Reports and bulletins were shared with government ministries and other interested institutions.

- Findings were sent to the district representatives of ministries, and presented at Nutrition and Food Security meetings.

Comments from evaluation (van der Heide A Evaluation of the sustainable nutrition rehabilitation project (SNRP) and review of the integrated nutrition and food security surveillance system (INFSSS). Action Against Hunger, Unpublished.) The bulletin was often published late, and while it was very readable for people with knowledge of the subject staff at district level found it difficult to understand. Interviewers and health surveillance assistants never saw the bulletin. 
Table 1 Three case studies of nutrition surveillance system administration in low-income countries (Continued)

The NSP was never transferred to the government HKI tried to build capacity in the IPHN through

secondment of staff, but this had little effect since

government policy is to regularly transfer personne

between functions after a number of years. When

the FSNSP started in 2009, the process of

institutionalisation was not delineated, but at least

this time it was identified as an activity in the

programme that needed separate support. So the

EU separately funded a programme within

Bangladesh Bureau of Statistics (BBS) called the

"Nutrition Surveillance Component Project" through

which the BBS conduct Post-Enumeration Checks

(PECs) for quality control and arrange training

programmes for capacity-building. Thus the process

of transferring the FSNSP from BRAC University and

Helen Keller International to the BBS has started,

although the exact manner remains to be finalised,

if the system finds a donor to sustain it One model

is for the BBS to take over the data collect

is for the BBS to take Over the data collection and

reporting from the JPGSPH, with HKl still being

involved with data analysis and training, and JPGSP

being responsible for quality control including PECS.

Alternatively health workers at community level could

undertake data collection.
The institutional base was transferred from Save the Children UK to the Disaster Prevention and Preparedness Commission (DPPC), Ministry of

Agriculture. In 1998, Save the Children UK decided to stop collecting data and, despite a 3-year plan to transfer skills, the system was not sustained after 2001. This was due to a lack of human and financial resources within the DPPC, formerly the RRC, to deal with nutrition.

Present-day surveillance is still coordinated by the Ministry of Agriculture and there are three main sources of information: existing programme data systems; ad hoc surveys using SMART methods in regions where early warning information indicates that the nutrition situation is deteriorating; and

bi-annual nutrition surveys in vulnerable regions, which are supported by UNICEF and partly funded by the UK Department for Internationa Development.
The intention was to transfer the institutional base from ACF to the Ministries of Health and Agriculture, and training and materials were

provided to enable this. However, from the start the system was perceived as belonging to ACF rather than the government, and this perception did not change during the operational period. One reason was that no single government structure was responsible for the INFSSS and no physical place was available to "house" the project within one of the two ministries or other governmental agency. the two ministies or other govennental agency. When funding for the system ended and ACF withdrew support, the system quickly began to decline. There was a lack of ownership, a lack of human resources to undertake data entry and analysis, and unclear roles and responsibilities among government employees.

The use of Rapid SMS technology was piloted in three clinics in 2009, and now a 'rapid surveillance system' for health facility and community screening is being established, supported by UNICEF and the EU.

Development


and the data cannot be disaggregated sufficiently to identify locations or socio-economic groups that are most in need of interventions. For this reason, some countries implement systems of repeated representative cross-sectional surveys with national or area-specific coverage, such as Bangladesh (Table 1) [74], Indonesia [75] and Nicaragua [76], while some countries use sentinel sites, such as the INFSS system in Malawi (Table 1) [77] and Mozambique [78]. Examples of data being used for local-level planning can be found in the reports of the Bangladesh and Indonesian surveillance systems. In the latter, vitamin A coverage and other nutritional indicators were used by individual districts for health budgeting purposes [79]. In the former, NSP data were used to assess the severity and magnitude of the impacts of disasters which guided relief and rehabilitation efforts in the 1990s. Partner NGOs refined geographical targeting and changed their methods of targeting, for example using data on income rather than data on the diet [74].

For local planning purposes in most countries, repeated surveys, which allow disaggregation of data at a low level of administration such as a district, are prohibitively expensive and this is therefore not necessarily the best approach. Instead there is potential for the better use of routinely collected administrative data $^{2}$ for local nutrition monitoring [72] provided that such data are interpreted with caution and with additional contextual information. Good examples of this type of use are available from Ghana [80], Ethiopia [81], Somalia [82], the Palestinian Territories [83] and Maharashtra state in India [84].

Nutrition surveillance data can also be used to monitor the effects of events and policies on poorer members of society, for example the impact of structural adjustment policies in the 1980s [39]; an economic crisis and the US Embargo in Cuba [85]; economic sanctions in Haiti [86]; simultaneous drought and financial crisis in Indonesia [87]; and the food price crisis in Zimbabwe [88].

\section{Evaluation of the nutritional impact of programmes and projects}

The evaluation of programmes was identified as one of the original goals of nutrition surveillance but in order to attribute changes in outcomes convincingly to programme activities, a custom designed survey is needed, that is, a prospective design with some form of both before-after measures, and comparisons either with-without the intervention, or with significant variation in exposure to the interventions to enable a dose-response effect to be detected. Given that most early nutrition surveillance systems used administrative data, it was not realistic to think that such data could be used to attribute impact and to assess effectiveness. However, administrative data can be a useful adjunct to custom data collection to evaluate the effectiveness of programmes, for example in Ethiopia [89]. Data collected for surveillance purposes are more useful for programme evaluation than administrative data and have been used to construct a plausible case both for the effectiveness of interventions, for example a social marketing campaign that promoted the consumption of darkgreen leafy vegetables and eggs in Indonesia [90], and for a lack of effectiveness, for example the National Nutrition Programme (NNP) in Bangladesh [74].

In contrast to estimates of effectiveness, it is relatively straightforward to monitor the implementation of programmes and projects as long as data are collected on process indicators such as access to and use of services, such as in the system in Nicaragua [91]. Some process indicators are collected in any case as part of national surveys such as DHS and MICS which can be used to check whether services are being delivered to the target group.

\section{Timely warning}

There are many situations in which nutrition surveillance data have been used to warn of a deteriorating nutrition situation and enable mitigating actions to be taken. For some systems this is the primary objective, such as the Bangladesh NSP when it was created in 1990 (Table 1), while for other systems timely warning is just one of a number of goals. Anthropometric status does not provide a good predictive indicator because of the time lag between exposure to causes of malnutrition and the outcome. Data that predict potentially harmful trends in food security or disease are more helpful, such as data on food prices or rainfall. Changes in dietary practices may occur at an early stage of a food crisis, and can be detected by surveillance because comparative data from previous years are available, so a change is noted. For example in Indonesia, surveillance data revealed that the quality of the diet rather than its quantity had changed during an economic crisis, when reduced access to animal and fortified foods led to lower dietary intakes of iron [92].

Several examples exist in Malawi of mitigating actions as a result of surveillance. Information from the Integrated Nutrition and Food Security Surveillance System (Table 1) was used mainly at the national level by the Malawi Vulnerability Assessment Committee (a consortium of government, NGOs and UN agencies) to trigger or scale up emergency responses [93]. For example, during the 2005 food crisis, information contributed to targeted scaling up of nutrition rehabilitation units, supplementary feeding programmes, community based therapeutic care, and school feeding programmes [94]. In Ethiopia, the Nutrition Surveillance Project (NSP) was primarily used as a tool to advocate for a response to provide food aid (Table 1). For example in 1997, surveillance information warned of a crisis in Wollo, and in 1998 an emergency 
was declared leading to distribution of food aid. The NSP also warned of a crisis in Wolayita in 2000, leading to nutrition surveys and the establishment of feeding centres [95].

For early warning in situations of chronic poverty and vulnerability, it is difficult to identify the point at which a "normal" situation becomes a crisis, both in urban [96, 97] and rural contexts [98]. In slow-onset food crises, early action often falls between time-bound humanitarian funding on the one hand and slowly responsive development funding on the other [99].

\section{Using information for action}

The early definitions of nutrition surveillance cited above, show that decision-making has always been a key objective $[2,21]$. However the connection between information and action is complex. Effective action to address nutrition issues at a national level is dependent on many factors apart from the existence of information or evidence. Such factors include leadership, prioritisation of nutrition, the policy context, and operational capacity [100]. Better knowledge of the politics of nutrition and an understanding of how best to drive political commitment to nutrition and turn it into action on the ground is needed [101]. Similarly in a humanitarian context, there is a history of warnings based on evidence that were not acted upon. A greater understanding of the politics and processes of decision making could increase the potential for timely and appropriate responses [102].

The needs of busy decision-makers have apparently not been borne in mind when planning and implementing nutrition surveillance systems. For example, findings need to be expressed in terms that are comprehensible to stakeholders who are not nutritionists, including government officials, people in civil society, and managers in the UN and donor agencies. In evaluations of two former surveillance systems, the outputs were described as being comprehensible only by nutrition experts (Table 1). A critical evaluation of a selection of more recent reports, and discussions with key informants indicated there is still much potential to improve the communication of findings, for example by simplifying terms, by producing separate reports for different types of users, and by having a stronger focus on the policy and programming implications of findings (Tuffrey, V. Nutrition surveillance systems: their use and value. London: Save the Children and Transform Nutrition, forthcoming.). Also, the information outputs are often not timely relative to the needs of decision-makers. Early warning systems can be powerful tools in maintaining access to basic foods, but to be effective rapid action must follow data collection. Unless the information generated is integrated effectively with decision-making processes, there is little justification for such systems. This is not all: the need for sustainability of surveillance has frequently been overlooked, and institutional issues are also important.

\section{Factors leading to lack of sustainability}

Ownership and sustainability are closely linked. In lowincome countries, where technical capacity may be lacking and resources may be stretched, external agencies have become involved with national surveillance systems, both in their funding and implementation, and many systems have not survived the decline or withdrawal of external support. This section discusses ownership and sustainability in relation to the connected themes of financial support, developing capacity, the location of the institutional base, the demand for data and participation in the processes of surveillance.

\section{Dependence on external financial support}

Few low-income countries can afford to invest in the infrastructure needed for strong surveillance systems. Thus sustainability, in addition to the relevance and success of capacity building efforts (see below), relates largely to whether there is sufficient interest among donors and other external agencies to support the system [95]. A key question faced by national governments, donors and other external agencies, is whether these systems offer value for money, and unfortunately it is impossible to address this except in very qualitative terms. Clearly, in the past, the decision was in some instances that they did not offer sufficient value in comparison with other demands on resources.

The cost-benefit ratio is likely to differ depending on the context, but the case is clearest for the purposes of timely warning. Depending on the size of the survey, around five years ago, the cost of an ad hoc survey of anthropometric status was between USD6,000 to USD14,000 [103, 104]. In Ethiopia, 509 surveys were carried out between 2000 and 2009 [105]. This is an average frequency of more than 1 per week at a cost of more than USD500,000 per year. It was calculated that the Save the Children (SC) surveillance system in Ethiopia (Table 1) had provided data from nearly four times as many sites and four times a year compared with the amount of data that could have been generated for the same cost per year by individual nutrition surveys [95]. At the time that SCUK stopped the NSP, the organisation perceived the cost of surveillance as expensive. But compared with the amount then spent on aid to Ethiopia, it was not expensive: the annual cost represented less than one per cent of the value of food aid delivered by the United States Agency for International Development (USAID) in non-emergency years [95].

It can be argued that a good early-warning mechanism that triggers a protective response is more cost-effective than having to support a full-scale humanitarian response to a nutritional emergency ([42], p.18). One can therefore justify an investment in closely monitoring food and nutrition security in highly vulnerable regions such as the Horn of Africa, to which many millions of 
dollars of humanitarian assistance are directed annually [106]. For example, the UK Department for International Development (DfID) is supporting nutrition surveillance in Ethiopia and will continue to do so at least until 2017. The difficulty of calculating the value for money of this support was noted by this donor, together with the observation that the nutrition data have a multiplier effect in terms of leveraging wider humanitarian expenditure, which totals $£ 200-£ 400$ million annually in Ethiopia, and helps to ensure that these larger resources are directed to where they are needed most [107].

Unfortunately donors work to budget cycles of 5 or 10 years at most, and their priorities change. In Bangladesh USAID funded the NSP from 1990 to 2002, a relatively long period in terms of programme support (Table 1). The Dutch government took over from USAID but then there was a gap in funding from 2006 until 2009, and it is now funded by the EU, although that support is coming to an end. The total EU contribution (90\%) is $€ 5.2$ million or about $€ 1$ million/year, and this represents a relatively small proportion of the total budget for Bangladesh managed by EuropeAid, which was $€ 131$ million in 2011 [108].

This level of support for a system would appear to be a good investment from a donor's perspective. Clearly it is impossible to demonstrate a causal link between surveillance activities and key outcome indicators. However in countries such as Bangladesh with a long tradition of collecting and using quantitative data, there is a plausible and convincing argument that investing in nutrition surveillance to provide information for policies and programmes in health and development offers good value for money. High-level users in Bangladesh habitually draw on the information provided by the FSNSP to justify and target nutrition-sensitive and nutrition-specific interventions and there is great potential to increase the utility of the system by improving the communication of information.

\section{Lack of capacity development}

Sustainability is not only linked to sufficient financial support, but also to the extent to which well-designed plans exist to build local capacity, and to the commitment and ability of a government to support the system. With these two factors in place, dependence on external assistance can be steadily reduced over time. Thus capacity building for planning and implementing national surveillance systems, both for individuals and institutions at different levels, is a vital element in building surveillance, yet in the past it has often been overlooked in favour of the technical issues.

Plans to build local capacity have often been poorly designed or absent, so systems do not survive the reduction or loss of external assistance. For example a lack of sufficient national capacity was identified as one of the main reasons the Ethiopian NSP did not survive the handover from SCUK [95] (Table 1). The commitment of the national government to building capacity is also vital. It is important that individuals who have become competent as a result of training and work experience are allowed to remain in post rather than be transferred to other unrelated positions. In the Malawi and Bangladesh surveillance systems (Table 1), many individuals who had been working as government counterparts of staff of the external agencies were moved from surveillance to other duties after a few years (Tuffrey, V. Nutrition surveillance systems: their use and value. London: Save the Children and Transform Nutrition, forthcoming.).

\section{Location of the institutional base}

It can be argued that information relating to health services and the systems for its supply are a "public good" as they meet the defining criteria of being nonexcludable $^{3}$ and non-rival ${ }^{4}$. Thus national governments have a primary responsibility to supply information on health and nutrition, both alone within their jurisdictions, and together with international agencies to allow international comparisons and global reviews.

Country governments are therefore the natural owners of national nutrition surveillance systems (although if there is a sensitive political environment, for example in Ethiopia in the 1990s [95], it may be preferable for the information to be provided from a source that is independent of government). In addition to this theoretical justification, there are practical reasons for integrating nutrition surveillance systems within government structures. First, surveillance information is intended for policy and planning purposes. Civil servants and politicians who are responsible for designing and implementing a country's food and nutrition policy must trust and understand the information, and the ownership of data by external experts may lead to remoteness and distance. Second, consistency in data collection needs a stable administration, and, while the priorities of donors and aid agencies often change, government structures are relatively permanent. Third, surveillance systems can be a mechanism for capacity building, and the skills, tools and infrastructure created can contribute generally to national development.

As discussed above, due to the high cost of surveillance, external institutions including UN agencies and non-governmental organisations have often been involved in funding and implementing systems. There is a disadvantage when the funder and implementer are the same institution: it can lead to institutional isolation which can reduce "buy-in" and therefore affect responses for example, the NSP in Ethiopia led by SCUK [95] (Table 1). As has already been mentioned, external 
bodies have often prioritised technical rather than institutional issues and so, historically, there has been little investment in developing capacity and a lack of planning to enable the transfer of the systems to governments once their capacity is sufficiently developed. This lack of planning and resourcing means that systems often do not survive in competition with the other national priorities of the government, such as in Malawi in 2008 (Table 1). A good model in this regard is the FSNSP in Bangladesh, where funding separate from that allocated to the surveillance activities was allocated to institutionalise the surveillance system within a government structure [109] (Table 1).

The location of the specific institutional base of national surveillance systems within government varies between countries. A recent review reported that in Guatemala, Indonesia, Mozambique, Nicaragua, Palestinian Territories, Sudan, Viet Nam and Zambia it is within the Ministry of Health; in Bangladesh it is located within the Ministry of Planning, and only in the Democratic Republic of Congo and Ethiopia is the Ministry of Agriculture mentioned [43].

The need to establish one central surveillance unit to be responsible specifically for data collection, analysis and interpretation, was highlighted in the most recent guide ([42], p.36). This reproduces advice provided in the very first guide, however the earlier advice also advocated care in the choice of the institutional base: - "The central unit should.. be closely associated with, or part of the planning apparatus in the government... not be within the responsibility of a specialized ministry itself (e.g. agriculture or health), but should rather provide them with the information they require". It was noted that in countries in which food and/or nutrition institutes exist, those might fulfil some functions of the central unit. The early guidance also emphasised that this unit should present the results in a way that is immediately understandable so that by identifying the implications for action, it becomes useful to those responsible for planning ([2], pp 43-4).

Given that resources may be targeted based on the findings of surveillance, a neutral institutional base for surveillance activities seems essential so that the findings can be perceived as impartial. The choice of the Ministry of Planning or equivalent seems ideal because of its neutral position with regard to sectors whose activities are designed to influence nutritional status and food security, especially the two key ministries of Health and Agriculture. It is possible that in some countries the clear ownership of surveillance outputs by one sector (usually health) has contributed to a lack of trust in the information, leading to a weak demand for the information which thus had an effect on sustainability.

\section{Lack of demand}

For the long-term sustainability of any public health activity, not only are there technical, institutional, and financial dimensions, there also needs to be social sustainability. In other words, there needs to be a pressure to continue. For nutrition surveillance there are many existing and potential users of the information that is produced, including officials and technical staff: in national and sub-national levels of government; in the health sector (national, district and local); in nongovernmental organisations (international, national, district and local); in inter-governmental organisations such as the UN agencies; in donor agencies; in academic institutions (local and international) and training institutions; in the media; and in the food industry, and last but not least, members of the general public.

Historically there has been little demand for nutrition surveillance information from sub-national levels and communities perhaps because, despite the identified benefits of decentralised planning and decision-making in nutrition [110], this is not a reality in most lowincome countries. Most of the demand for information comes from people at national or international levels. As the recent global financial crisis has meant that development budgets are increasingly under scrutiny, donors need proof of success, so accountability for expenditure is becoming more important. Also UN bodies, donors and civil society would like to track progress towards international goals such as Millennium Development Goals and the WHA targets, and regular data on nutrition outcomes can demonstrate governments' accountability in this regard [111]. These factors have helped stimulate the current major global initiative to support health information systems in low income countries [112] which will have the benefit for nutrition surveillance of enhancing the quality and quantity of nutrition data from health systems. This has contributed to recent initiatives to support national level nutrition information systems ([14], p.113) and surveillance systems [113]. Thus there is both external demand and potential external support for countries to compile and analyse their information, and this is increasingly the case within the context of the UN "data revolution" initiative with respect to sustainable development [114]. With respect to nutrition data in low-income countries, the data revolution entails increasing the credibility of data collected; focussing data collection on a set of core outcome indicators; and ensuring that comparable time series data are collected regularly, rather than necessarily collecting more data ([14], p.113-114). Ways to address these three issues are discussed elsewhere (Tuffrey V, Hall A. Methods of nutrition surveillance in low-income countries. Emerging Themes in Epidemiology, forthcoming.).

It also needs to be recognised that tracking targets may not be a top priority for national governments, and there might be an element of reluctance if the data show that the country is not performing well in comparison 
with others. If the demand for the information is mainly from external sources and is used to name and shame, it is hardly surprising that some governments do not prioritise surveillance activities.

Nutrition surveillance information can also be used for advocacy, another aspect of accountability, and this role in influencing the basic causes of malnutrition has long been recognised [52]. The establishment and strengthening of civil society in countries involved in the Scaling up Nutrition (SUN) movement [115] is likely to increase the demand for information. Organisations other than those implementing the surveillance system are best placed to assess accountability and use the information for advocacy, since institutions responsible for surveillance need to remain independent in order to protect the credibility of the information. Ideally the surveillance unit would build links with organizations that are better placed to undertake advocacy and involve them with the system's design and data analysis. For example in Maharashtra state in India, two civil society movements have helped raise awareness about child undernutrition which has increased pressure on local government and has held officials to account ([84], p.76).

\section{Lack of participation}

The fifth and final factor to be considered relating to sustainability is participation, which is strongly linked with the previous factor, demand. Historically surveillance systems have been designed by information experts and technicians who tend to be removed from the decision-making process, and thus the information has needed to be "sold" to the potential users [116]. Also if information from surveillance activities is to be used in decision-making, the users of information need to be involved, at least at the design stage, otherwise they may doubt the credibility of the information or not fully understand it. It might be argued that the application of scientific methods, together with provision of a detailed description of the methods employed, should be sufficient to ensure that findings are credible. However personal and political differences may hinder this rational approach. In addition to the planning stage, although it is less likely to be feasible, decision-makers ideally would also be involved with other stages of the surveillance process including data analysis, interpretation, and cost sharing.

The issue of participation also relates to stakeholders at a sub-national level. Food and nutrition surveillance information has generally supported a top-down planning process and is used as a basis for sectoral actions. Information generated at the community level has rarely been fed back to support local decision-making. For example, in an evaluation of nutrition surveillance in Botswana it was reported that some of the district- and clinic-level health staff had never seen a report from the system ([117], p.4); similar observations were made in an evaluation of the Malawi INFSS system (Table 1). The lack of involvement of stakeholders at lower levels and the need to increase their participation is often mentioned in the literature (for example, [42, 118-120]). The justification partly relates to the quality and use of data, which are linked: if those who collect data then use the resulting information, there should be more incentive for them to collect high quality data. Thus it can be argued that the local use of data collected at lower levels of an information system is vital to improving the quality of data, and this in turn increases demand and strengthens sustainability.

This issue is particularly relevant where surveillance is dependent on data collected by health workers, who may see this as a burdensome task, taking time from their primary function to provide health care. For example, in the INFSS system in Malawi (Table 1) the quality of data collected was found often to be poor and incomplete, and district surveillance committees were suggested as a mechanism to link their district's own data with its use [93]. More recently similar issues were identified in the sentinel site surveillance system in Mozambique, where no analysis of the data was conducted at the clinic, district, or provincial level, and clinic teams mentioned that they did not know why they were collecting the data ([78], p.7). The decentralization of information management to district level is said to be an effective strategy to improve routine information systems [121]. The case for decentralized data management in nutrition surveillance systems was made long ago $[122,123]$ and applied in Haiti [124] and Thailand [125], but no evidence has been seen of existing systems where this occurs.

The justification for the participation of all stakeholders also has an ethical dimension: a human-rights based approach to nutrition action demands the active involvement of beneficiaries in processes to improve nutrition [126]. In this vein in Central America nearly 30 years ago, an additional role for food and nutrition surveillance activities beyond policy and programming was identified. It was argued that they could contribute to the food security and socioeconomic development of the poor if the activities were designed, operated, and evaluated by communities organized at the grass-roots level [127]. This was apparently not operationalised with much success, since only one example was found in the literature (from Sudan) [128]. Sentinel sites may have a role to play in a more participatory model of nutrition surveillance in future where the data are collected for local use, and community members participate in deciding what to assess and how to design and implement solutions ([129], p.131). Participatory nutrition surveillance is not congruent with the requirement to track a 
consistent set of indicators in order to monitor subnational and national trends in nutrition and exposures. The lack of participatory systems revealed by the literature review indicates that to date, for those designing activities for nutrition surveillance, the balance between generating data for monitoring that are useful at community level and those which that are internationally comparable has been tilted in favour of the latter.

\section{Other critical issues for future and sustainable nutrition surveillance \\ Harnessing developments in electronic technology}

Taking advantage of technological innovation has been a theme throughout the history of nutrition surveillance, from drawing on food security assessments informed by satellite data in the 1980s, through computer assisted interviewing in the 1990s, to the development of "real time monitoring" (RTM) in the last decade including the use of mobile phones [130]. In this context "real time" means very recently collected data often collected frequently using information and communication technology (ICT) [121].

It is recognised that despite the efficiencies that electronic devices might bring, human input will continue and this source of error will remain large and consequential, even in high-income contexts where surveillance systems are likely to be very sophisticated [131]. Developments in technology are likely to help mainly with data collection, collation, analysis and dissemination, but cannot replace human contributions to planning, designing systems and interpreting data.

As well as technical challenges to real time monitoring, such as internet band width and the need for operations research [46], there are more general challenges. Real time monitoring initiatives commonly involve partnerships between the state, civil society, donors and the private sector, each of which will inevitably have different objectives and priorities. It will be important to ensure that the quality of data and equity are given precedence over other potentially conflicting priorities inherent in the necessary partnerships between public and private stakeholders, so common guidance must be adopted on both quality and equity [132]. Priority should be given to ensuring there is sufficient power to disaggregate data on socially excluded groups and by sex, focusing on addressing horizontal equity and inclusivity, and to gathering specific evidence on the poorest and most economically vulnerable, specifically focusing on addressing vertical equity and inclusivity [132]. Another challenge is to build cultural bridges between three diverse stakeholder groups: the youthful technological community who are promoting modern methods, the seasoned humanitarian policy and programme makers in conventional development, and the communities that are the subjects of surveillance [46].

\section{Surveillance of overnutrition}

For the past forty years the focus of nutrition surveillance in low-income countries has been undernutrition, but its role needs to be expanded to include overnutrition as many of these countries experience the nutrition transition and face the major health challenges associated with this [133]. Attention to overweight and obesity in global nutrition targets is a recent development. The fourth WHA target specifically states that there should be no increase in child overweight [9]. Targets of the Sustainable Development Goals are to reduce premature deaths from non-communicable diseases and "end malnutrition in all its forms" [10] and overweight is now explicitly included in the characterization of malnutrition. For example the many countries which were signatories to the Declaration of the Second International Conference on Nutrition acknowledged that "different forms of malnutrition co-exist within most countries" and that malnutrition included "undernourishment, stunting, wasting, underweight and overweight in children under 5 years of age; and anaemia in women and children among other micronutrient deficiencies" [11].

Evidence indicates that as policies to address poverty succeed and rates of stunting and wasting decline, there is a concomitant rise in child overweight, apparently driven by rapidly changing diets consequent to growth in disposable incomes, lifestyle changes and urbanisation, yet very few low-income countries systematically monitor trends in overweight [134]. Internal demand will increase for such information to support policy and planning at subnational level to prevent the growing burden of noncommunicable diseases related to overweight, especially because of the major long-term costs for health-care systems and from lost economic contributions [135]. As is the case for surveillance of undernutrition, a challenge for those planning activities for surveillance of overnutrition will be to balance the needs for internationally comparable monitoring data and data that are useful at the local level.

\section{The interface between the national and international nutrition systems}

From the perspective of national nutrition leaders, guidance provided by the international nutrition system is intermittent and lacks consistency, both between organisations and over time. Similarly, the perspective of decision-makers in national nutrition policy is that the international nutrition system is indifferent to the political realities and timetables of nations, and lacks clear priorities [100]. The challenge associated with the recent international initiatives to strengthen surveillance activities [113] and to bring together nutrition and food security data to promote analysis that is relevant to policy ([14], p.113) will be for the international community both to leave these initiatives at the top of the priority 
list and to assure countries that this will remain the case: that surveillance systems and information platforms are not additional strategies which are prioritised today and will be replaced by another more important priority tomorrow. Also in deliberations about strengthening or creating surveillance activities, nutrition decision-makers must be at centre stage, not those who are providing technical advice and external resources. It is essential to get this right, given the important role that nutrition surveillance information can have in boosting national and subnational policy-making, planning and programming, and thereby reducing the incidence of malnutrition.

\section{Constraints on successful multisectoral activities in nutrition}

The last theme to have emerged from this review of the development of surveillance over the past forty years and which provides an insight into future directions for nutrition surveillance, is the repetition of history. Multisectoral nutrition planning was the dominant paradigm in world food and nutrition policy between about 1974 and 1980. This paradigm stressed the need to recognise child malnutrition as a structural problem with many causes based in poverty and underdevelopment, and emphasised that nutrition interventions should be multisectoral and integrated into overall national development policies [136]. Food and nutrition surveillance systems were expected to be of a "..multi-sectoral nature" and provide information that contributed to the planning process [2].

This paradigm is apparently returning (notwithstanding outstanding questions over whether investments should focus on true multisectoral integration, or simply programme co-location [19]). Multisectoral activities have been identified as key to reducing stunting [137], and lessons learnt from recent initiatives have been documented [138-140]. The need to move beyond unitary to multisectoral approaches to address chronic disease caused by overnutrition in low-income countries is also recognised [135]. Two of the main factors argued to account for the previous decline in the paradigm [136] no longer apply, first that the approach required much more data than any low-income country could or wanted to provide, and second that the systems analysis was too complicated. The third reason identified for the decline of the paradigm was that it was based on the false assumption that nutrition would become a political priority. It turned out that most governments were not interested, and those few that were interested could not convince their different ministries to be coordinated in recognition of the intersectoral causes of poor nutrition [136]. This is the only major hurdle which now remains to be overcome.

The difference now compared with forty years ago is the existence of the SUN movement in many countries, and through this, the establishment of multisectoral platforms to catalyse and enable complementary, coordinated, and integrated action [20]. The SUN movement is also a platform for leaders to get together and drive nutrition forwards [141]. It remains to be seen whether the SUN movement will be able to overcome the challenges of weak capacity and resistance to collaboration between sectors, and turn nutrition into a political priority in each country. If it does, effective information and knowledge management, including high quality nutrition surveillance, will be in great demand.

\section{Conclusions}

Information from nutrition surveillance is still used to provide early warning, to develop policies, to guide planning and programmes, and to contribute to evaluation. There is a renewed emphasis on undernutrition internationally. Governments have committed to address this issue in their countries, and now longitudinal data are needed to tackle questions of equity and accountability. Thus nutrition surveillance has a new and important potential role as an accountability mechanism, both to track progress towards international targets and to provide process data to track resource management and accountability within programmes.

This review of nutrition surveillance activities suggests that to be sustainable there needs to be the following: demand for the information; reasonable cost and costefficiency of the process; speedy generation and dissemination of good quality information; secure allocation of resources from the government and/or donor; and one central organising institution for strong co-ordination of data collection, analysis, interpretation and communication. An investment in local institutional and individual capacity plus the retention of experienced staff is important and, ideally, the coordinating institution should sit within a government structure separated from those relating to health or agriculture. A periodic evaluation of the process and of the system's efficiency needs to be inbuilt. Ideally more and higher quality data should come from existing sources rather than setting up new systems. Those who lead surveillance need to be independent of decision-makers but should prioritise the needs of decision-makers for information. The presentation and communication of findings needs to be done in terms that are understood by the target audience. And last but not least, to promote participation, findings should be shared with stakeholders at all levels.

Other critical issues for the future of useful and sustainable nutrition surveillance include ensuring that both equity and data quality are prioritised when harnessing recent developments in electronic technology; developing activities for effective surveillance of overnutrition; safeguarding the related issues of quality, availability and 
use of data on the international nutrition agenda; ensuring national rather than international stakeholders are at centre stage during the design of surveillance activities; and ensuring that history is not repeated with respect to the demise of multisectoral approaches for addressing poor nutrition, due to lack of capacity and resistance to collaboration. It is hoped that insights from this paper will aid practitioners and agencies to amend or design sustainable surveillance activities, since the need ".. to watch over nutrition, in order to make decisions which lead to improvements in nutrition in populations" [21] is as critical now as when nutrition surveillance was first promoted by the WHO [2], forty years ago.

\section{Endnotes}

${ }^{1}$ The surveillance system described in this guidance is effectively a food and nutrition information system, since the role of the system is described as "..to provide continuous analysis, integration and interpretation of data from multiple sources, ensuring a systematic flow of information from different sectors" [42]. Given the potential confusion between the terms surveillance system and information system it may be best if the term 'nutrition surveillance system' is reserved for systems in which primary data are collected regularly. Proposed definitions are as follows: A nutrition surveillance system is a system, co-ordinated by a central institution, that collects primary data that are statistically representative of the population at recurrent intervals on indicators of nutrition and the factors that influence them, for making decisions. Nutrition surveillance is regular and systematic collection of data on nutritional indicators (Tuffrey V, Hall A. Methods of nutrition surveillance in low-income countries. Emerging Themes in Epidemiology, forthcoming.).

${ }^{2}$ Administrative sources are collections of data held by other parts of government (external to the statistical agency), which are gathered and used for the purposes of administering taxes, benefits or services.

${ }^{3}$ Once the information is in the public domain it is difficult to withhold from users.

${ }^{4}$ The consumption of information does not lessen its availability for use by others.

\section{Competing interests}

The author declares that she has no competing interests.

\section{Authors' contributions}

$V T$ undertook the research and drafted the manuscript.

\section{Acknowledgements}

The study forms part of the Transform Nutrition programme of research (see www.transformnutrition.org) funded by UK aid. The author was a consultant with Save the Children. Technical input and review was provided by Andrew Hall. We are most grateful to all the experts who agreed to be interviewed as part of this study, for their time and insights, and also to the reviewers of this paper for valuable comments. Thanks are due to Helen Keller International for hosting the author's visit to Dhaka.
Received: 13 June 2015 Accepted: 24 February 2016

Published online: 08 March 2016

\section{References}

1. WHO. Health topics - Public health surveillance. 2015. http://www.who.int/ topics/public_health_surveillance/en/. Accessed 13 February 2015.

2. WHO. Methodology of Nutritional Surveillance. Report of a Joint FAO/ UNICEF/WHO Expert Committee. Geneva: World Health Organization; 1976. Available from: http://whqlibdoc.who.int/trs/WHO_TRS_593.pdf. Accessed 1 June 2015.

3. World Bank. Repositioning Nutrition as Central to Development, A Strategy for Large-Scale Action. Washington: The International Bank for Reconstruction and Development/The World Bank; 2006.

4. Stein AJ, Qaim M. The human and economic cost of hidden hunger. Food Nutr Bull. 2007;28(2):125-34.

5. African Union Commission NEPAD UNECA and WFP. The Cost of Hunger in Africa: Social and Economic Impact of Child Undernutrition in Egypt, Ethiopia, Swaziland, and Uganda. Background paper. Addis Ababa: African Union Commission, New Partnership for Africa's Development Planning and Coordinating Agency, United Nations Economic Commission for Africa, and UN World Food Programme; 2014.

6. Horton S, Steckel R. Malnutrition. Global economic losses attributable to malnutrition 1900-2000 and projections to 2050: Copenhagen Consensus on Human Challenges; 2011. Available from: http://www.copenhagenconsensus. com/sites/default/files/malnutrition.pdf. Accessed 28 May 2015.

7. Horton S, Hoddinott J. Benefits and Costs of the Food and Nutrition Targets for the Post-2015 Development Agenda Post-2015 Consensus: Copenhagen Consensus Centre. 2014. Available from: http://www.copenhagenconsensus. com/publication/post-2015-consensus-food-security-and-nutritionperspective-horton-hoddinott. Accessed 2 June 2015.

8. DfID. Nutrition for Growth Commitments: Executive Summary. London: Department for International Development; 2013. Available from: https://www.gov.uk/government/uploads/system/uploads/attachment_data/ file/207271/nutrition-for-growth-commitments.pdf. Accessed 1 June 2015.

9. WHO. Indicators for the Global Monitoring Framework on Maternal, Infant and Young Child Nutrition. Geneva: World Health Organization; 2014.

10. United Nations. Transforming our world: the 2030 agenda for sustainable development. New York: United Nations; 2015.

11. FAO, WHO. Conference outcome document: Rome Declaration on Nutrition. Second International Conference on Nutrition. Rome: FAO and WHO; 2014.

12. Haddad L, Acosta AM, Fanzo J. Accelerating Reductions in Undernutrition, What can nutrition governance tell us? University of Sussex. Brighton: Institute of Development Studies; 2012.

13. International Food and Policy Research Institute (IFPRI). Global Nutrition Report 2014: Actions and accountability to accelerate the world's progress on nutrition. Washington: IFPRl; 2014.

14. International Food and Policy Research Institute (IFPRI). Global Nutrition Report 2015: Actions and accountability to advance nutrition and sustainable development. Washington: IFPRI; 2015.

15. Barrett CB, Headey D. Measuring Resilience in a Volatile World: A Proposal for a Multicountry System of Sentinel Sites. Washington: International Food Policy Research Institute; 2014.

16. Black RE, Victora CG, Walker SP, Bhutta ZA, Christian P, de Onis M, et al. Maternal and child undernutrition and overweight in low-income and middle-income countries. Lancet. 2013;382(9890):427-51.

17. Grantham-McGregor S, Cheung YB, Cueto S, Glewwe P, Richter L, Strupp B. Developmental potential in the first 5 years for children in developing countries. Lancet. 2007;369(9555):60-70.

18. Bhutta ZA, Das JK, Rizvi A, Gaffey MF, Walker N, Horton S, et al. Evidencebased interventions for improvement of maternal and child nutrition: what can be done and at what cost? Lancet. 2013:382(9890):452-77.

19. Ruel MT, Alderman H, the Maternal and Child Nutrition Study Group. Nutrition-sensitive interventions and programmes: how can they help to accelerate progress in improving maternal and child nutrition? Lancet. 2013:382(9891):536-51

20. Gillespie S, Haddad L, Mannar V, Menon P, Nisbett N. The politics of reducing malnutrition: building commitment and accelerating progress. Lancet. 2013;382(9891):552-69.

21. Mason J, Habicht JP, Tabatabai H, Valverde V. Nutritional surveillance. Geneva: World Health Organization; 1984. 
22. Daza CH, Read MS. Health-related components of a nutritional surveillance system. Bull Pan Am Health Organ. 1980;14(4):327-36.

23. Serdula M, Herman D, Williamson D, Binkin NJ, Aphane J, Trowbridge F. Validity of clinic-based nutritional surveillance for prevalence estimation of undernutrition. Bull World Health Organ. 1987;65(4):529.

24. WHO. Guidelines for the Development of a Food and Nutrition Surveillance System for Countries in the Eastern Mediterranean Region. Alexandria: WHO Regional Office for the Eastern Mediterranean; 1989.

25. Pelletier DL, Msukwa LAH. The use of national sample surveys for nutritional surveillance: lessons from Malawi's national sample survey of agriculture. Soc Sci Med. 1991;32(8):887-98.

26. Delgado $H$, Palma P, Fischer $M$. The use of the height census of schoolchildren in Central America and Panama. Food Nutr Bull. 1991;13(1):17-9.

27. Delgado $\mathrm{HL}$, Palmieri M. Sentinel surveillance in health and nutrition: experience in Guatemala. Food Nutr Bull. 1994;15(4):303-7.

28. Amador M, Pena M. Nutrition and health issues in Cuba: strategies for a developing country. Food Nutr Bull. 1991;13(4):311-7.

29. Autier P, D'Altilia JP, Delamalle JP, Vercruysse $V$. The food and nutrition surveillance systems of Chad and Mali: the "SAP" after two years. Disasters. 1989;13(1):9-32.

30. Brooks RM, Abunain D, Karyadi D, Sumarno I, Williamson D, Latham MC, et al. A timely warning and intervention system for preventing food crises in Indonesia: applying guidelines for nutrition surveillance. Food Nutr (Roma). 1985;11(2):37-43

31. de Pee S, Bloem MW, Sari M, Kiess L, Yip R, Kosen S. The high prevalence of low hemoglobin concentration among Indonesian infants aged 3-5 months is related to maternal anemia. J Nutr. 2002;132(8):2215-21.

32. Berger SG, de Pee S, Bloem MW, Halati S, Semba RD. Malnutrition and morbidity are higher in children who are missed by periodic vitamin A capsule distribution for child survival in rural Indonesia. J Nutr. 2007:137(5):1328-33

33. Campbell AA, Akhter N, Sun K, De Pee S, Kraemer K, Moench-Pfanner R, et al. Relationship of household food insecurity to anaemia in children aged 6-59 months among families in rural Indonesia. Ann Trop Paediatr. 2011;31(4):321-30

34. Shafique S, Akhter N, Stallkamp G, de Pee S, Panagides D, Bloem MW. Trends of under- and overweight among rural and urban poor women indicate the double burden of malnutrition in Bangladesh. Int J Epidemiol. 2007;36(2):449-57

35. Best CM, Sun K, de Pee S, Bloem MW, Stallkamp G, Semba RD. Parental tobacco use is associated with increased risk of child malnutrition in Bangladesh. Nutrition. 2007;23(10):731-8.

36. Campbell AA, de Pee S, Sun K, Kraemer K, Thorne-Lyman A, MoenchPfanner $\mathrm{R}$, et al. Household rice expenditure and maternal and child nutritional status in Bangladesh. J Nutr. 2010;140(1):189S-94.

37. Torlesse H, Kiess L, Bloem MW. Association of household rice expenditure with child nutritional status indicates a role for macroeconomic food policy in combating malnutrition. J Nutr. 2003;133(5):1320-5.

38. Semba RD, de Pee S, Sun K, Sari M, Akhter N, Bloem MW. Effect of parental formal education on risk of child stunting in Indonesia and Bangladesh: a cross-sectional study. Lancet. 2008;371(9609):322-8.

39. Ismail SJ. Nutritional surveillance: experiences from developing countries Proc Nutr Soc. 1991:50(3):673-9.

40. Maire B, Beghin I, Delpeuch F, Kolsteren P. Nutritional surveillance: a sustainable operational approach. Studies in Health Services Organisation \& Policy. Antwerp: ITG Press; 2001.

41. Bilukha O, Prudhon C, Moloney G, Hailey P, Doledec D. Measuring anthropometric indicators through nutrition surveillance in humanitarian settings: options, issues, and ways forward. Food Nutr Bull. 2012;33(2):169-76.

42. WHO. Food and nutrition surveillance systems Technical guide for the development of a food and nutrition surveillance system. Cairo: World Health Organization Regional Office for the Eastern Mediterranean; 2013.

43. Friedman G. Review of National Nutrition Surveillance Systems. Washington: Food and Nutrition Technical Assistance III Project (FANTA); 2014.

44. Jones AD, Ngure FM, Pelto G, Young SL. What are we assessing when we measure food security? A compendium and review of current metrics. Adv Nutr. 2013;4(5):481-505.

45. Pangaribowo EH, Gerber N, Torero M. Food and Nutrition Security Indicators: A Review: Center for Development Research (ZEF). University of Bonn; 2013. Available from: http://www.foodsecure.eu/PublicationDetail. aspx?id=13. Accessed 2 June 2015.
46. Mock N, Morrow N, Papendieck A. From complexity to food security decision-support: novel methods of assessment and their role in enhancing the timeliness and relevance of food and nutrition security information. Global Food Security. 2013;2(1):41-9.

47. United Nations. Report of the World Food Conference, Rome, 5-16 November, 1974. New York: United Nations; 1975.

48. UNICEF and Cornell Nutritional Surveillance Program. Social and Nutritional Surveillance in Eastern \& Southern Africa, Background Papers for Workshop Nairobi, Kenya 17-19 May 1982; 1982. Available from: http://pdf.usaid.gov/ pdf_docs/PNAAM857.pdf. Accessed 2 June 2015.

49. Sen A. Poverty and famines: an essay on entitlement and deprivation. Oxford: Oxford University Press; 1981.

50. Morgan R. The development and applications of a Drought Early Warning System in Botswana. Disasters. 1985;9(1):44-50.

51. Mewaee A. Ethiopia case study. In: Carter JP, editor. Famine in Africa. Amsterdam: Pergamon; 1982. p. 13-4

52. Mason JB, Mitchell JT. Nutritional surveillance. Bull World Health Organ. 1983;61(5):745-55.

53. Scrimshaw NS, editor. Surveillance for actions towards better nutrition. Food and Nutrition Bulletin 16(2). Japan: United Nations University Press; 1995

54. Babu S, Quinn V, editors. Special Issue Household Food Security and Nutrition Monitoring: The African Experience. Food Policy 19(3). Oxford: Butterworth-Heinemann Ltd; 1994.

55. UNICEF. Strategy for improved nutrition of children and women in developing countries. New York: UNICEF; 1990.

56. Devereux S, Baulch B, Hussein K, Shoham J, Sida H, Wilcock D. Improving the analysis of Food Insecurity - Food Security Measurement, Livelihoods Approaches and Policy: Applications in FIVIMS: Unpublished report prepared for the Food Insecurity and Vulnerability Information and Mapping Systems (FIVIMS) Secretariat. 2004.

57. FAO, WHO. World Declaration and Plan of Action for Nutrition. Rome: Food and Agriculture Organization and World Health Organization of the United Nations; 1992

58. Woodruff $B$, Corbett M, Barriquault A. Integration of assessments of child nutritional status and household food security: Save the Children International. 2013. Available from: http://www.nutritionworks.org.uk/images/content-media/ publications/programme-review-and-evaluation/2010-onward/report\%20-\% 20scf\%20hh\%20food\%20security\%20-\%20final.pdf. Accessed 2 June 2015.

59. SMART. Measuring Mortality, Nutritional Status, and Food Security in Crisis Situations: SMART Methodology; 2006. Available from: http://smartmethodology.org/survey-planning-tools/smart-methodology/. Accessed 2 June 2015

60. de Pee S, Bloem MW, Gorstein J, Sari M, Satoto, Yip R, et al. Reappraisal of the role of vegetables in the vitamin A status of mothers in Central Java, Indonesia. Am J Clin Nutr. 1998;68(5):1068-74.

61. Berger SG, de Pee S, Bloem MW, Halati S, Semba RD. Malnutrition and morbidity among children not reached by the national vitamin $A$ capsule programme in urban slum areas of Indonesia. Public Health. 2008:122(4):371-8.

62. Campbell AA, Thorne-Lyman A, Sun K, de Pee S, Kraemer K, MoenchPfanner $\mathrm{R}$, et al. Indonesian women of childbearing age are at greater risk of clinical vitamin A deficiency in families that spend more on rice and less on fruits/vegetables and animal-based foods. Nutr Res. 2009; 29(2):75-81

63. Campbell AA, Akhter N, Sun K, de Pee S, Kraemer K, Moench-Pfanner R, et al. Relationship of homestead food production with night blindness among children below 5 years of age in Bangladesh. Public Health Nutr. 2011;14(9):1627-31.

64. Aburto N, Rogers L, de-Regil M, Kuruchittham V, Rob G, Arif R, et al. An evaluation of a global vitamin and mineral nutrition surveillance system. Arch Latinoam Nutr. 2013;63(2):105-13.

65. Hancioglu A, Arnold F. Measuring coverage in $\mathrm{MNCH}$ : tracking progress in health for women and children using DHS and MICS household surveys. PLOS Med. 2013:10(5):e1001391.

66. Fiedler JL. Towards overcoming the food consumption information gap: strengthening household consumption and expenditures surveys for food and nutrition policymaking. Global Food Security. 2013:2(1):56-63.

67. Carletto C, Zezza A, Banerjee R. Towards better measurement of household food security: harmonizing indicators and the role of household surveys. Global Food Security. 2013;2(1):30-40. 
68. FAO. Summary of Proceedings: Measurement and Assessment of Food Deprivation and Undernutrition. International Scientific Symposium, 26-28 June 2002, Rome. Rome: Food Insecurity and Vulnerability Information and Mapping Systems (FIVIMS) Secretariat, Food and Agriculture Organisation; 2002. Available from: http://www.fao.org/docrep/005/Y4249E/y4249e00.htm. Accessed 2 June 2015

69. FAO. International Scientific Symposium on Food and Nutrition Security information: from Valid Measurement to Effective Decision Making 17-19 Jan 2012. Rome: Food and Agriculture Organization; 2013. Available from: http://www.fao.org/docrep/017/i3244e/i3244e.pdf. Accessed 2 June 2015.

70. Chopra M, Hassan N, Klaver W, Rahman A, de Pee S. External review of the nutritional surveillance project in Bangladesh: Commissioned by the Royal Government of the Kingdom of the Netherlands. 2004.

71. Helen Keller International Indonesia. Nutrition and Health Surveillance System Close out report 2003. Jakarta: Helen Keller International Indonesia; 2004.

72. WHO. A draft framework for the global monitoring of the Comprehensive Implementation Plan on Maternal, Infant and Young Child Nutrition (6 September 2013): World Health Organization; 2013. Available from: http://www.who.int/nutrition/events/2013_consultation_indicators_ globalmonitoringframework_WHO_MIYCN.pdf. Accessed 2 June 2015.

73. Smith LC, Haddad L. Reducing child undernutrition: past drivers and priorities for the post-MDG era. World Dev. 2015;68:180-204.

74. Akhter N, Haselow N. Using data from a nationally representative nutrition surveillance system to assess trends and influence nutrition programs and policy. Field Actions Science Reports. 2010;4:1-7.

75. Thorne-Lyman A. Insights from 25 years of Helen Keller International's nutrition surveillance in Bangladesh and Indonesia. In: Haytmanek E, McClure K, editors. Mitigating the nutritional impacts of the global food price crisis: workshop summary. Washington: National Academies Press; 2010. p. 82-5.

76. Jefferds ME. Integrated Surveillance System for Nutrition Interventions in Nicaragua (SIVIN). A2Z Cornerstone Meeting, June 13, 20112011.

77. Blaschke S, Bokenkamp K, Cosmaciuc R, Denby M, Hailu B, Short R. Using mobile phones to improve child nutrition surveillance in Malawi, UNICEF Malawi and UNICEF Innovations. New York: Columbia School of International and Public Affairs; 2009.

78. Doledec D. Analysis of the Sentinel Site Nutrition Surveillance System in Mozambique. Washington: FHI 360/Food and Nutrition Technical Assistance III Project (FANTA); 2014.

79. Helen Keller International Bangladesh. Nutritional Surveillance Project USAID Cooperative Agreement No. 388-A-00-99-00060-00 September 1999 - November 2002: Helen Keller Worldwide; 2003. Available from: http://pdf.usaid.gov/pdf_docs/pdabx780.pdf. Accessed 2 June 2015

80. Shoham J, Watson F, Dolan C. The use of nutritional indicators in surveillance systems. London: Nutrition Works and Overseas Development Institute; 2001.

81. Emergency Nutrition Coordination Unit - Ethiopia. Emergency Nutrition Quarterly Bulletin, First Quarter 2013. Ethiopia: Emergency Nutrition Coordination Unit; 2013.

82. Food Security and Nutrition Analysis Unit - Somalia. Nutrition Update November - December 2013. 2013.

83. Palestinian Ministry of Health and UNICEF. National Nutrition Surveillance Report Highlights January - June 2011; 2011. Available from: http://www. unicef.org/oPt/NNSS_Mld_year_report.pdf. Accessed 2 June 2015.

84. Haddad L, Nisbett M, Barnett I, Valli E. Maharashtra's child stunting declines: what is driving them? Findings of a multidisciplinary analysis. Brighton: Institute of Development Studies; 2014

85. Garfield R, Santana S. The impact of the economic crisis and the US embargo on health in Cuba. Am J Public Health. 1997;87(1):15-20.

86. Gibbons E, Garfield R. The impact of economic sanctions on health and human rights in Haiti, 1991-1994. Am J Public Health. 1999;89(10):1499-504.

87. Block SA, Kiess L, Webb P, Kosen S, Moench-Pfanner R, Bloem MW, et al. Macro shocks and micro outcomes: child nutrition during Indonesia's crisis. Econ Hum Biol. 2004;2(1):21-44

88. Mason JB. Nutrition surveillance in relation to the food price and economic crises. In: Haytmanek E, McClure K, editors. Mitigating the nutritional impacts of the global food price crisis: workshop summary. Washington: National Academies Press; 2010. p. 76-82.

89. White J, Mason J. Assessing the impact on child nutrition of the Ethiopia Community-based Nutrition Program. New Orleans: Tulane University School of Public Health and Tropical Medicine; 2012.
90. Helen Keller International Indonesia. Summary and accomplishments of the HKI/GOI Collaboration for Vitamin A, 1999-2005. Jakarta: Helen Keller International Indonesia; 2006.

91. Mora JO. Integrated system for nutrition program monitoring and evaluation (SIVIN) Brief review of the experience after 3 years of implementation (2003-2005). Micronutrient Forum Meeting, 16-18 April 2007. Istanbul: Nicaragua Ministry of Health; 2007.

92. Kiess Jr L, Moench-Phanner R, Bloem MW, Pee S, Sari M, Kosen S. New conceptual thinking about surveillance: using micronutrient status to assess the impact of economic crises on health and nutrition. Malays J Nutr. 2000;6(2):223-32.

93. Teller C. Technical assessment of data quality and information use of the Malawi integrated nutrition and food security surveillance system. Rome: Food and Agriculture Organization; 2008. Available from: https://www. yumpu.com/en/document/view/9349659/technical-assessment-of-dataquality-and-information-use-of-the-. Accessed 28 February 2016.

94. Oliphant N. Nutrition Surveillance in Malawi. Unpublished working paper for short course "Nutrition Information Systems in Eastern and Southern Africa" Cape Town, University of the Western Cape, 20-24 August 2007: Tulane University School of Public Health and University of the Western Cape; 2005.

95. Watson F, Dolan C, Shoham J, Buchanan-Smith M. A Review of Save the Children UK's Nutritional Surveillance Programme in Ethiopia. London: Nutrition Works, International Public Nutrition Resource Group; 2006.

96. Oxfam GB Concern Worldwide \& CARE International. The Nairobi Informal Settlements: An emerging food security emergency within extreme chronic poverty - a compilation and synthesis of key food security, livelihood, nutrition and public health data: Oxfam GB, Concern Worldwide and CARE International in Kenya; 2009.

97. Schofield L, Mohamed S, Kimani-Murage E, Wekesah F, Mberu B, Egondi T, et al. Spotting the invisible crisis: early warning indicators in urban slums of Nairobi, Kenya. Field Exchange. 2013;46:55-9.

98. Mack Smith S. Food Crisis in the Horn of Africa Progress Report July 2011 July 2012. Oxford: Oxfam International; 2012.

99. Bailey R. Managing famine risk, linking early warning to early action. London: The Royal Institute of International Affairs; 2013.

100. Bryce J, Coitinho D, Darnton-Hill I, Pelletier D, Pinstrup-Andersen P. Maternal and child undernutrition: effective action at national level. Lancet. 2008; 371(9611):510-26.

101. Nisbett N, Gillespie S, Haddad L, Harris J. Why worry about the politics of childhood undernutrition? World Dev. 2014;64:420-33.

102. Darcy J, Stobaugh H, Walker P, Maxwell D. The Use of Evidence in Humanitarian Decision Making ACAPS Operational Learning Paper. Somerville: Feinstein International Centre; 2013.

103. Oguta T, Moloney G, Masese L. Piloting LQAS in Somaliland. Field Exchange. 2008;33:26.

104. Muzeiyn Z, Yohannes E. Maintaining GOAL's capacity to support surveillance in Ethiopia. Field Exchange. 2011:40:61.

105. Watson F, Negussie B, Dolan C, Shoham J, Hall A. Quality and potential use of data collected during nutrition surveys: an analysis of surveys in Ethiopia. International Health. 2011;3(2):85-90.

106. Headey D, Ecker O. Improving the measurement of food security. Washington: International Food Policy Research Institute; 2012.

107. DfID. Project Completion Review, Humanitarian Support to UNICEF Nutrition Surveillance. London: Department for International Development; 2014.

108. European Union. Annual Report 2012 on the European Union's Development and external assistance policies and their implementation in 2011. Luxembourg: Publications Office of the European Union; 2012.

109. Bangladesh Bureau of Statistics. Annual Report on Post Enumeration Check (PEC) of Food Security-Nutritional Surveillance 2012. Dhaka: Bangladesh Ministry of Planning, Statistics and Information Division; 2014.

110. Gillespie S, Mason J, Martorell R. How Nutrition Improves - Nutrition policy discussion paper No. 15. Geneva: United Nations Administrative Committee on Coordination, Subcommittee on Nutrition (ACC/SCN); 1996.

111. te Lintelo D. Accountability for International Nutrition Commitment Initiatives. Brighton: Institute of Development Studies; 2014.

112. WHO. Country Health Information Systems A review of the current situation and trends. Geneva: World Health Organization; 2011.

113. WHO. Accelerating Nutrition Improvements in Sub-Saharan Africa (ANI). 2015. http://www.who.int/nutrition/ANI_project/en/. Accessed 23 February 2015. 
114. Independent Expert Advisory Group on a Data Revolution for Sustainable Development (IEAG). A world that counts: mobilising the data revolution for sustainable development. New York: Independent Expert Advisory Group Secretariat; 2014

115. Scaling up Nutrition. Civil Society Network. 2015. http://scalingupnutrition. org/the-sun-network/civil-society-network. Accessed 26 February 2015

116. Arnauld J, Alarcon J, Immink M. Food security and food and nutrition surveillance in Central America: the need for functional approaches. Food Nutr Bull. 1990;12(1):26-33.

117. Bailes A. National Nutrition Surveillance system: A review and recommendation report, Supported by UNICEF Botswana: Unpublished report for the Botswana Ministry of Health Food and Nutrition Unit, Family Health Division; 2006.

118. Chotard S. Developing Nutrition Surveillance within the framework of EOS in Ethiopia: Unpublished report for UNICEF Ethiopia; 2005.

119. Schelling E. Enhanced enrolment of pastoralists in the implementation and evaluation of the UNICEF-FAO-WFP Resilience Strategy in Somalia. Nairobi: UNICEF Eastern and Southern Africa Regional Office (ESARO); 2013.

120. Pelletier DL, Porter CM, Aarons GA, Wuehler SE, Neufeld LM. Expanding the frontiers of population nutrition research: new questions, new methods, and new approaches. Adv Nutr. 2013;4(1):92-114.

121. Lucas H, Greeley M, Roelen K. Real time monitoring for the most vulnerable: concepts and methods. IDS Bull. 2013;44(2):15-30.

122. Mulder-Sibanda M, Chowdhury RI. Decentralized data management in nutritional surveillance for timely warning and intervention. Disasters. 1995;19(2):140-7.

123. Babu S, Chapasuka E. Mitigating the effects of drought through food security and nutrition monitoring: lessons from Malawi. Food Nutr Bull. 1997;18(1):71-81.

124. Mulder-Sibanda M, Sibanda-Mulder FS, d'Alois L, Verna D. Malnutrition in food-surplus areas: experience from nutritional surveillance for decentralized planning in Haiti. Food Nutr Bull. 2002;23(3):253-61.

125. Valyasevi A, Winichagoon P, Dhanamitta S. Community-based surveillance for action towards health and nutrition: experience in Thailand. Food Nutr Bull. 1995;16(2):120-5.

126. Gillespie SR. Strengthening capacity to improve nutrition. Washington DC: International Food Policy Research Institute; 2001.

127. Immink MDC. Community-based food and nutrition surveillance as an instrument of socio-economic development in Central America: a point of view. Food Nutr Bull. 1988;10(4):13-5.

128. Ahmed $A E$, Ahmed IA. Nutrition surveillance in the Sudan: a communitybased approach. East Mediterr Health J. 1996;2(2):229-35.

129. Elder L, Kiess L. Nutrition toolkit tool \#2:- basic facts: nuts and bolts on nutrition. Annex A data collection methods and statistics. Washington: The World Bank; 2004. Available from: http://siteresources.worldbank.org/ NUTRITION/Resources/Tool2-AnnexA.pdf. Accessed 1 June 2015.

130. Barnett I, Edwards E. Mobile phones for real-time surveillance: approaches, challenges and opportunities for the data presentation and dissemination. Brighton: Institute of Development Studies; 2014.

131. Thacker SB, Qualters JR, Lee LM. Public health surveillance in the United States: evolution and challenges. Morb Mortal Wkly Rep. 2012;61(Supplement):3-9.

132. Greeley M, Lucas H, Chai J, Cummins M. Introduction: real time monitoring for the most vulnerable-investing in common guidance for equity and quality. IDS Bull. 2013;44(2):1-14.

133. Popkin BM, Adair LS, Ng SW. Global nutrition transition and the pandemic of obesity in developing countries. Nutr Rev. 2012;70(1):3-21.

134. Webb P, Luo H, Gentilini U. Measuring multiple facets of malnutrition simultaneously: the missing link in setting nutrition targets and policymaking. Food Security. 2015:1-14.

135. Rogers B. Hunger and Malnutrition: Copenhagen Consensus. 2012.

136. Jonsson $U$. The rise and fall of paradigms in world food and nutrition policy. (Commentary). World Nutrition. 2010;3:128-58.

137. Casanovas MC, Lutter CK, Mangasaryan N, Mwadime R, Hajeebhoy N, Aguilar AM, et al. Multi-sectoral interventions for healthy growth. Matern Child Nutr. 2013;9(S2):46-57.

138. Acosta AM, Fanzo J. Fighting Maternal and Child Malnutrition: analysing the political and institutional determinants of delivering a national multisectoral response in six countries. Brighton: Institute of Development Studies; 2012.

139. Levinson FJ, Balarajan Y. Addressing malnutrition multisectorally, what have we learned from recent international experience? New York: UNICEF and MDG Achievement Fund; 2013.
140. Garrett J, Natalicchio M. Working multisectorally in nutrition, principles, practices, and case studies. Washington: International Food Policy Research Institute; 2011.

141. Scaling up Nutrition. Country Network. 2015. http://scalingupnutrition.org/ the-sun-network/country-network. Accessed 26 February 2015.

142. Bloem MW, Moench-Pfanner R, Panagides D. Health \& nutritional surveillance for development. Singapore: Helen Keller International, Asia Pacific Regional Office; 2003.

143. Helen Keller International and BRAC Institute of Global Health. State of Food Security \& Nutrition in Bangladesh 2013. Dhaka: Helen Keller International and BRAC Institute of Global Health; 2014.

144. DfID. Annual review - humanitarian support to UNICEF nutrition surveillance 2013. London: Department for International Development; 2013.

145. Rivero E, Salse N, Zapatero E. Integrated nutrition and food security surveillance in Malawi. Field Exchange. 2008;33:21-3.

146. Zambrano R, Seward RK. Mobile technologies and innovation: case studies in m-governance. New York: UNDP; 2014.

\section{Submit your next manuscript to BioMed Central and we will help you at every step:}

- We accept pre-submission inquiries

- Our selector tool helps you to find the most relevant journal

- We provide round the clock customer support

- Convenient online submission

- Thorough peer review

- Inclusion in PubMed and all major indexing services

- Maximum visibility for your research

Submit your manuscript at www.biomedcentral.com/submit
C Biomed Central 